anales de psicología, 2017, vol. 33, $\mathrm{n}^{\circ} 1$ (january), 26-31

http://dx.doi.org/10.6018/analesps.33.1.232201
(C) Copyright 2017: Servicio de Publicaciones de la Universidad de Murcia. Murcia (Spain) ISSN print edition: 0212-9728. ISSN web edition (http://revistas.um.es/analesps): 1695-2294

\title{
Psychometric properties of the Short Leyton Obsessional Inventory-Child Version in a community sample of Spanish children and adolescents
}

\author{
Marina Iniesta-Sepúlveda1,*, Ana I. Rosa-Alcázar ${ }^{2}$, Beatriz Ruíz García ${ }^{3}$ y José Antonio López-Pina ${ }^{2}$ \\ ${ }^{1}$ Catholic University of Murcia, Faculty of Health Sciences (Spain). \\ ${ }^{2}$ University of Murcia, Faculty of Psychology (Spain). \\ ${ }^{3}$ Morales Meseguer Hospital. Public Health Service. Murcia (Spain).
}

\begin{abstract}
Título: Propiedades psicométricas del Inventario Obsesivo de Leyton para Niños-Versión Corta en una muestra comunitaria de niños y adolescentes Resumen: El objetivo de este estudio fue analizar las propiedades psicométricas del Short LOI-CV en una muestra española comunitaria. Los participantes fueron 914 niños y adolescentes con edad media de 13.01 años (varones $=51.3 \%$ ). El AFE mostró un modelo de tres factores compuesto por los dominios Obsesiones, Compulsiones y Limpieza. Tanto la puntuación total como las subescalas mostraron una adecuada consistencia interna. La versión española mostró buena fiabilidad test-retest y moderada validez convergente y discriminante. Los participantes más jóvenes (8 a 10 años) obtuvieron medias más altas que la escala Total y distintas subescalas que los mayores (grupo de 11-13 y de 14-18 años). Se encontraron también diferencias significativas respecto al sexo, siendo los varones los que mayores medias mostraron en la escala de compulsiones. Pese a que es necesaria más investigación, estos resultados sugirieron que la versión en español del Short LOI-CV mostró un buen rendimiento psicométricos para evaluar los síntomas obsesivo-compulsivos en niños y adolescentes en población comunitaria.
\end{abstract}

Palabras clave: Trastorno obsesivo-compulsivo; Short LOI-CV; niños; adolescentes.

\section{Introduction}

Obsessive-compulsive disorder (OCD) is characterized by the presence of obsessions and compulsions (APA, 2013) that are similar in both adults and youth, and cause a significant personal, academic, and social impairment (AACAP, 2012). Age of onset of OCD seems to have a bimodal distribution with one peak in childhood and another peak in early adulthood (Geller, 2006). Approximately $40 \%$ of childhood-onset OCD cases continue to suffer the disorder in adulthood (Bloch et al., 2009). Heyman, Fombonne, Simmons, Ford, Meltzer, and Goodman (2001) reported prevalence rates of $.25 \%$, in youth from 5 to 15 years old, and pointed that almost $90 \%$ of the cases detected had not been identified previously. Overall prevalence rates reported in DSM-V ranged from $1 \%$ to $1.8 \%$ (APA, 2013) being the prevalence figures influenced by gender (De Mathis et al., 2001).

Research findings in psychological and pharmacological interventions have suggested that early detection and treatment can improve the prognosis in many cases (Leonard et al., 1993; Rosa-Alcázar, Iniesta-Sepúlveda, \& Rosa-Alcázar, 2012; Rosa-Alcázar et al., 2015; Sánchez-Meca, RosaAlcázar, Iniesta-Sepúlveda, \& Rosa-Alcázar, 2014).

* Dirección para correspondencia [Correspondence address]: Marina Iniesta Sepúlveda Faculty of Health Sciences Campus de Los Jerónimos Catholic University of Murcia 30107-Murcia (España).

E-mail:miniesta@ucam.edu
Abstract: The aim of the current study was to analyze psychometric properties of the Short LOI-CV in Spanish community sample. Participants were 914 children and adolescents with a mean age of 13.01 years $(51.3 \%$ males). The EFA yielded a three-factor model representing Obsessions, Compulsions, and Cleanliness dimensions. Both, total score and subscales showed an adequate internal consistency. The Spanish version also exhibited good test-retest reliability and moderate convergent and discriminant validity. The younger participants (from 8 to 10 years) obtained higher means for total score and subscales than older participants (groups 11-13 and 14-18 years). Significant differences related to gender were also observed since males obtained higher means in Compulsions subscale. Despite more research is required, this results suggested that Spanish version of the Short LOI-CV showed a good psychometric performance assessing obsessive-compulsive symptoms in community population.

Key words: Obsessive-compulsive disorder; Short LOI-CV; children; adolescents.

However, there are a lot of youth with OCD who do not receive an adequate intervention (Heyman et al., 2001) sometimes due to the lack of an early diagnosis. In the Practice Parameters for the assessment of children and adolescents with OCD, routine screenings for the presence of obsessive-compulsive symptoms is recommended (AACAP, 2012).

Several disorder-specific measures to assess OCD in children and adolescents have been developed and tested in the last decades. According the review conducted by IniestaSepúlveda, Rosa-Alcázar, Rosa-Alcázar, and Storch (2014) in the field of pediatric OCD symptoms and severity exist well-established assessments, the clinical interview Children's Yale-Brown Obsessive-Compulsive Scale (CY-BOCS, Scahill et al., 1997); approaching well-established assessments, the self-report Obsessive Compulsive InventoryChild Version (OCI-CV; Foa et al., 2010), and promising assessments such as the self-reports Children's Florida Obsessive-Compulsive Inventory (C-FOCI; Storch et al., 2009), the Children's Obsessional Compulsive Inventory (CHOCI; Shafran, Frampton, Heyman, Reynolds, Teachman, \& Rachman, 2003). The Leyton Obsessional Inventory - Child Version (LOI-CV; Berg, Whitaker, Davies, Flament, \& Rapoport, 1988) was classified as insufficiently tested.

The LOI-CV contains 20-items describing frequent obsessive-compulsive symptoms, which are rated according to presence or absence, and interference with one's daily routines. Analysis of their structure showed a 4-factor model, including General Obsessive, Dirt/Contamination, Numbers/Look, and School factors. Bamber et al. (2002) revised 
the original structure of LOI-CV in a community sample, finding an 11-item solution with 3 factors: Compulsions (items 1, 15, 19 and 20), Obsessions/Incompleteness (items 16, 17 and 18) and Cleanliness (items 4, 7 and 8). This brief version was denominated Short LOI-CV.

Despite the LOI-CV was the first self-report measure designed to assess obsessive-compulsive symptoms in children and adolescents; this was classified as insufficiently tested in the mentioned review, mainly based on the contradictory results obtained by the studies (Iniesta-Sepúlveda et al., 2014). Coefficients alpha ranged from .74 to .90 for the whole scale (Bamber et al., 2002; Canals, Hernández-Martínez, Cosi, Lázaro, \& Toro, 2011; King, Inglis, Jenkins, Myerson, \& Ollendick, 1995; Storch et al., 2011). However, internal consistency coefficients for subscales were between poor and good for General Obsessive (.53-.81), and poor for the rest of the subscales: Dirt/Contamination (.49-.65), Numbers/Look (.65-.66), and School (.49-.56) according two studies (Berg et al. 1988; Storch et al., 2011). The LOI-CV showed test-retest reliability ranging from .72 to .83 , but this was poor in children between 8 and 10 years $(r=.51$; King et al., 1995). The sensitivity and specificity of the LOICV showed values of $75 \%$ and $84 \%$ respectively, for a cutoff score $\geq 25$ (Flament et al., 1988) and $82.4 \%$ and $84.1 \%$ for a 20 cut-off score (Canals et al., 2011). However, Stewart, Ceranoglu, O'Hanley, \& Geller (2005) obtained 36\% and $27 \%$ for cut-off scores of 20 and 25 , respectively. Storch et al. (2011) also found poor sensitivity (14\%) for LOI-CV. The results regarding convergent validity were also contradictory since the LOI-CV did not show significant correlations with the CY-BOCS in some studies (Roussos et al., 2003; Storch et al., 2011).

Although the Short LOI-CV showed better psychometric properties than the complete version, some results are also contradictory. Alpha coefficient was high for the total score (.86) and adequate for subscales (.73 to .75). The sensitivity and specificity of the measure were $78 \%$ and $70 \%$ respectively for a 5 cut-off score. However in a sample of children and adolescents with OCD, Storch et al. (2011) obtained an alpha coefficient for total score of .65, and from .33 to .64 for subscales. In addition, the Short LOI-CV did not show significant correlations with the CY-BOCS, Child Depression Inventory -CDI- (Kovacs, 1992), and Internalizing and Externalizing subscales of Child Behavior Checklist -CBCL(Achenbach, 1991).

Brief self-report measures like the Short LOI-CV could be useful tools to detect OCD at an early stage, in both clinical and non-clinical populations. In addition, the first steps in epidemiological studies require having reliable and valid screening instruments with a quick and easy administration. Moreover, measures must be adapted to be used with different populations in order to avoid generalizations based race/ethnic/culture and to contribute to the dissemination of evidence-based assessment procedures (Huey \& Polo, 2008). The Short LOI-CV has not been sufficiently studied yet. For example, there are no psychometric data about the test-retest reliability, and the contradictory results about internal consistency and validity need to be clarified.

Having all of this in mind, the goals of the current study were: a) to evaluate the psychometric properties and factor structure of the Short LOI-CV in Spanish sample, b) to examine the convergent and discriminant validity of the Spanish version, and c) to explore the existence of significant differences related to gender and age of participants.

\section{Method}

\section{Participants}

Nine hundred and fourteen children and adolescents from $2^{\text {nd }}$ to $4^{\text {th }}$ grades of secondary public schools in Spain and aged between 8 and 18 years old were recruited as part of a larger school screening for OCD. Exclusion criteria were current/recent psychiatric illness or learning difficulties. The mean age was 13.01 years old (SD = 2.1). The percentage of male participants was $51.3 \%$, and there was no significant differences in gender distribution $(p=.427)$. With respect to the nationality, $88.2 \%$ were born in Spain, 5.9\% in Latin America, 3.5\% in Africa, $1.5 \%$ in the rest of Europe, $.7 \%$ in Asia, and $.2 \%$ in the USA. All children were fluent in Spanish.

There were not ceiling or floor effects because only a $10.8 \%$ of participants obtained the lowest total score, and only a $.1 \%$ of participants obtained the highest values. There were no missing data since children who did not answer all items were removed from data base.

\section{Instruments}

Short Leyton Obsessional Inventory-Child Version (LOI-CV). The Short LOI-CV is an 11-item self-report questionnaire to assess obsessive-compulsive symptoms in pediatric population. The items were rated according to a 4-point Likert scale. A more detailed description of characteristics and psychometric properties of the Short LOI-CV was provided above.

Obsessive Compulsive Inventory-Child Version (OCI-CV). The OCI-CV (Foa et al., 2010) is a 21-item self-report designed to be used in youth with OCD from 7 to 17 years. Items are scored on a 3-point Likert scale and total score ranges from 0 to 42. Internal structure includes 6 dimensions (Doubt/Checking, Obsessions, Hoarding, Washing, Ordering and Neutralizing). The OCI-CV showed excellent psychometric properties in a clinical sample of 109 children and adolescents with OCD (Foa et al., 2010) with internal consistency coefficients over .80 , and test-retest reliability of .77 for total score, and from .68 to .89 for subscales. The OCI-CV has shown good psychometric properties in Spanish children and adolescents (Rosa- 
Alcázar, Ruiz-García, Iniesta-Sepúlveda, López-Pina, \& Parada-Navas, 2014).

Maudsley Obsessional-Compulsive Inventory (MOCI). The MOCI (Hodgson \& Rachman, 1977) is a self-report containing 30 dichotomous items. Fonseca-Pedrero, Paino, \& Lemos-Giráldez (2007) examined psychometric properties of the MOCI in a sample of $\mathrm{S} \mathrm{p}$ a $\mathrm{nis} h$ adolescents (12- 19 years) observing good internal consistency for all subscales: Checking $(a=.87)$, Cleanliness $(a=.87)$ and Slowness $(a=.87)$.

Children's Depression Inventory (CDI). The CDI (Kovacs, 1992) is one of the most commonly used measures for the identification of depressive symptoms in children and adolescents from 7 to 15 years. The 27 items of the CDI are grouped in two subscales: dysphoria and self-esteem. This measure showed good psychometric properties in Spanish sample (Frías, Del Barrio, \& Mestre, 1991).

\section{Procedure}

The items of the LOI-CV were translated using the method of back-translation (Muñiz, Elosua, \& Hambleton, 2013). Each item was translated into Spanish by two independent Spanish bilingual psychologists. The two translations were compared and discussed until a consensual version was obtained. This Spanish version was translated back to English by two independent English bilingual psychologists. Finally the inverse translation version was compared with the original version, examining incongruences in the meaning of the items and making the pertinent modifications. Next, the Spanish version of the Short LOI$\mathrm{CV}$ was tested in a preliminary sample of 20 participants (Mean age $=9.5 \pm 1.6)$ with the objective of correcting any misunderstood items.

In order to collect data, the researchers provided information to directors of public schools, regarding the objectives and procedures involved in the study. Finally, six schools in Murcia and four in Castilla-La Mancha participated in this study. After obtaining informed consent from parents, children completed questionnaires during class time. Some measures could not be completed by all participants due to some of them were for a higher age range; these were MOCI (from 12 to 18 years) and CDI (from 8 to 15). Data were collected in presence of one of the authors (BR). No incentives were given for participation in the study.

\section{Data Analysis}

An item analysis was conducted in order to examine homogeneity of each item in relation to the total score. Symmetry and kurtosis coefficients were also calculated.
In order to analyze the internal structure of the Short LOI-CV an EFA was conducted on the 11-item polychoric matrix using the Factor software (Lorenzo-Seva \& Ferrando, 2006). Estimation of parameters method was the Unweighted Least Squares, rotating factorial structure with Promax Oblique method. To select the factors, Parallel Analysis was used (Timmerman \& Lorenzo-Seva, 2011).

Alpha coefficients were computed to test internal consistency of total score and subscales. Test-retest correlations were calculated to test reliability of complete scale and subscales. Pearson correlations were also computed to assess convergent and discriminant validity between Short LOI-CV and other OCD (MOCI, OCI-CV), and depression (CDI) measures. Finally ANOVAs were computed to explore gender differences in total score of the short LOI-CV and subscales. The software used was SPSS 21.

\section{Results}

\section{Analysis of items}

Descriptive statistics and corrected item-test correlations for each item of the Short LOI-CV are shown in Table 1.

Table 1. Descriptive statistics and item analysis of Short LOI-CV.

\begin{tabular}{lccccc}
\hline Item & Average & $S D$ & Item-total correlation & Skewness & Kurtosis \\
\hline 1 & .467 & .679 & .395 & 1.598 & 2.806 \\
4 & .618 & .909 & .402 & 1.432 & 1.078 \\
7 & .534 & .808 & .353 & 1.577 & 1.909 \\
14 & .510 & .704 & .321 & 1.607 & 2.994 \\
8 & .555 & .838 & .463 & 1.614 & 1.976 \\
15 & .481 & .705 & .462 & 1.651 & 2.910 \\
16 & .509 & .768 & .410 & 1.591 & 2.128 \\
17 & .589 & .825 & .385 & 1.439 & 1.491 \\
18 & .549 & .728 & .442 & 1.388 & 1.864 \\
19 & .423 & .559 & .258 & 1.228 & 2.379 \\
20 & .427 & .590 & .371 & 1.393 & 2.645 \\
\hline
\end{tabular}

Note: $S D=$ Standard deviation.

As it would be expected in community samples, item means were low. The high values of symmetry and Kurtosis coefficients ( $>2$ in some items) showed no normal distribution of item scores, furthermore the rationale of conducted the EFA on polychoric correlation matrix was evidenced.

All item-total correlations were over 0.30 with the exception of item 19. However this item was retained in order not to modify the original scale.

Table 2 reports means and standard deviations for each item response category. 
Table 2. Frequencies, means, and standard deviations for response categories in each item.

\begin{tabular}{lcccccccc}
\hline ITEM & \multicolumn{2}{c}{ Category 0 } & \multicolumn{2}{c}{ Category 1 } & \multicolumn{2}{c}{ Category 2 } & \multicolumn{2}{c}{ Category 3 } \\
\hline & Freq & $M(S D)$ & Freq & $M(S D)$ & Freq & $M(S D)$ & Freq & $M(S D)$ \\
\hline 1 & 562 & $4.04(3.51)$ & 299 & $7.55(3.25)$ & 31 & $12.03(6.78)$ & 22 & $12.41(6.25)$ \\
4 & 549 & $4.03(3.15)$ & 234 & $6.74(3.32)$ & 62 & $7.85(3.93)$ & 69 & $13.01(5.87)$ \\
7 & 567 & $4.21(3.78)$ & 249 & $6.96(2.74)$ & 55 & $9.18(5.09)$ & 43 & $12.79(5.41)$ \\
14 & 529 & $4.29(4.21)$ & 335 & $7.08(2.67)$ & 19 & $10.37(5.25)$ & 31 & $12.45(6.45)$ \\
8 & 559 & $3.91(3.11)$ & 259 & $7.19(3.11)$ & 40 & $8.90(4.72)$ & 56 & $13.73(5.86)$ \\
15 & 559 & $4.10(3.58)$ & 298 & $7.07(2.68)$ & 29 & $10.93(5.40)$ & 28 & $16.43(5.95)$ \\
16 & 570 & $4.06(3.43)$ & 257 & $7.32(3.11)$ & 53 & $9.70(5.05)$ & 34 & $13.71(6.35)$ \\
17 & 529 & $3.92(3.35)$ & 279 & $7.11(3.51)$ & 59 & $8.83(4.26)$ & 47 & $12.64(5.88)$ \\
18 & 514 & $3.81(3.60)$ & 325 & $7.21(2.91)$ & 48 & $9.92(4.67)$ & 27 & $14.70(6.25)$ \\
19 & 549 & $4.61(4.55)$ & 352 & $6.89(2.73)$ & 4 & $15.25(3.40)$ & 9 & $17.56(5.57)$ \\
20 & 560 & $4.41(4.24)$ & 329 & $6.96(2.28)$ & 14 & $14.07(5.51)$ & 11 & $19.82(5.23)$ \\
\hline
\end{tabular}

As it can be seen in Table 2, means showed an adequate increased shift from 0 to 4 points. Despite the item 19 maintained this growing tendency across response categories, frequency distributions in the lowest categories reveal the low importance placed on this symptom in community samples. This fact was already evidenced in the reduced item total correlations obtained for this item.

\section{Structural Validity}

The highly significance of Bartlett statistic, $\chi^{2}(55)=$ 2324.9, $\mathrm{p}<.001$, and the Keiser-Meyer-Olkin test, KMO $=.776$, reflected that polychoric correlation matrix contained enough significant values to conduct an EFA. This analysis yielded a three-factor solution (Table 3), being equivalent to the original model reported by Bamber et al. (2002). The first dimension, Obsessions/ Incompleteness, included items (16, 17, and 18) about doing things correctly, the second factor named Compulsions included items $(1,14,15,19$, and 20) related to numbers and luck, and the third factor, Cleanliness was represented by items (4, 7, and 8) describing obsessions and compulsions about cleaning. These three factors explained a $65.5 \%$ of total variance of correlation matrix.

Table 3. Promax rotated loadings of Short LOI-CV

\begin{tabular}{lccc}
\hline \multirow{2}{*}{ Item } & FactorFactor Factor \\
& I & II & III \\
\hline 17. I worried a lot if I did something not exactly & & & \\
the way I liked & .765 & -.132 & .012 \\
16. I often felt guilty because I had done some- & & & \\
thing &. $\mathbf{7 0 7}$ & .046 & $\mathbf{- . 0 6 5}$ \\
18. I kept on thinking about things that I had & & & \\
done & .408 & .265 & .103 \\
19. I moved or talked in a special way & -.129 & $\mathbf{. 9 4 3}$ & -.087 \\
20. I had special numbers or words & -.116 & $\mathbf{. 9 0 3}$ & .055 \\
14. I was fussy about keeping my hands clean & .225 & $\mathbf{. 6 2 0}$ & -.135 \\
15. I had a special number & .088 & $\mathbf{. 6 0 0}$ & .145 \\
1. I felt I had to do certain things & .294 & $\mathbf{. 3 4 2}$ & .111 \\
8. I was fussy about keeping my hands clean & -.030 & .034 & $\mathbf{. 8 0 5}$ \\
4. I hated dirt and dirty things. & .111 & -.168 & $\mathbf{. 7 0 0}$ \\
7. I worried about being clean enough. & -.098 & .082 & $\mathbf{. 6 9 4}$ \\
\hline Note: Factor loadings pertaining to each factor are in bold. & &
\end{tabular}

\section{Descriptive statistics}

Means and standard deviations for the Short LOI-CV total score and subscales and for the other measures used in the current study are reported in Table 4. As we expected the distribution of the scores in all variables showed a positive bias. The highest mean was obtained in Obsessions subscale, $M=3.36, S D=3.14$, and Compulsions subscale, $M=2.31, S D=2.21$. In the OCI-CV only $.1 \%$ participants obtained a total score of 34 while the $1 \%$ obtained the lowest score $(0), M=12.05, S D=$ 6.36. In the MOCI the highest score (22) was obtained by $0.2 \%$ of sample and the lowest (0) by $30.2 \%, M=$ 2.47, $S D=3.41$. The highest score in CDI was 49 and it was obtained by $.1 \%$ of sample and the lowest (0) by $0.8 \%$, $M=10.67, S D=6.58$.

Table 4. Descriptive statistics in Spanish community sample.

\begin{tabular}{lcccc}
\hline Instrument & $N$ & Mean & $S D$ & Skewness \\
\hline LOI-CV & 914 & 5.67 & 4.32 & 1.18 \\
Compulsions & & 1.80 & 1.82 & 1.01 \\
Obsessions & & 1.66 & 1.75 & 1.48 \\
Cleanliness & & 1.71 & 2.03 & 1.68 \\
OCI-CV Total & 914 & 12.05 & 6.36 & .38 \\
MOCI & 776 & 2.47 & 3.41 & 2.00 \\
CDI & 539 & 10.67 & 6.58 & 1.30
\end{tabular}

Notes: LOI-CV = Leyton Obsessional Inventory- Child Version, OCI-CV $=$ Obsessive Compulsive Inventory Child-Version, MOCI = Maudsley Obsessional-Compulsive Inventory; CDI = Children's Depression Inventory.

\section{Internal consistency and reliability}

Alpha coefficients were acceptable for total score $(\alpha=$ .74), Compulsions $(\alpha=.71)$ and Cleanliness, $(\alpha=.71)$, but poor for Obsessions/Incompleteness $(\alpha=.59)$.

Test-retest data of a random sample representing 20\% $(n=183)$ were collected after two weeks. There were no significant group differences, neither in symptom measures, $(p>.05)$ nor in demographic characteristics $(p>.05)$. Testretest reliability was high for the Short LOI-CV total score $(r=.79,95 \% C I=.76-.81)$, and for the subscales Obsessions/Incompleteness $(r=.76,95 \% C I=.73-79)$, Compulsions $(r=.77,95 \% C I=.74-.80)$ and cleanliness $(r=.77$, $95 \% \mathrm{CI}=.74-.80)$.

\section{Age and gender differences}

Age and gender differences in obsessive-compulsive symptom severity were also examined. Results showed a weak but statistically significant relationship between child age and Short LOI-CV total scale $(r=-.135, p<.001)$, Obsessions/Incompleteness $(r=-.101, p=.002)$, and Cleanliness $(r=-.228, p<.001)$ subscales. Compulsions subscale was not significantly associated with age $(r=.021, p=$ .522). Participants from 8 to 10 years obtained a higher 
mean $(M=8.19)$ than participants from 11 to 13 years $(M$ $=5.14)$, and from 14 to 18 years $(M=5.48)$.

ANOVA results on total score of the Short LOI$\mathrm{CV}$ showed no significant differences for gender $(\phi=$ $.654)$ and for the gender $\mathrm{x}$ age interaction $(p=.905)$, but there were significant differences between the three groups of ages $\left[F(2,906)=24.01, p<.001, \omega^{2}=.048\right]$, but the effect size was poor.

For Obsessions/Incompleteness subscale there were no significant effects of gender $(p=.623)$, and gender $x$ age interaction $(p=.934)$. An age effect was observed. Children from 8 to 10 years showed a higher mean $(M=5.15)$ than children from 11 to 13 years $(M=3.28)$, and from 14 to $18\left(M=2.92, F(2,906)=5.95, p=.003, \omega^{2}=.011\right)$. For Compulsions, there were significant effects of gender $\left[F(1,906)=6.56, p=.011, \omega^{2}=.012\right.$; Male $=2.698, \mathrm{Fe}-$ male $=2.281]$ and age $\left[F(2,906)=20.75, p<.001, \omega^{2}=\right.$ .041 ; Mean 8-10 $=3.041$, Mean 11-13 = 1.864, Mean 14-18 $=2.564]$. The gender $\mathrm{x}$ age interaction was no significant $(p=.532)$. F or Cleanliness there was no significant effect of gender $(p=.198)$ but we found a significant effects of a ge $[F(2,906)=28.93, p<.001$, $\left.\omega^{2}=.058\right]$, and gender $\mathrm{x}$ age interaction $[F(2,906)=4.45, p$ $\left.=.012, \omega^{2}=.007\right]$. All effect sizes were poor.

\section{Convergent and discriminant validity}

The Sort LOI-CV total score showed significant but moderate relationship with total score of the OCI-CV $(r=$ $.32, p<.001)$, and MOCI $(r=.45, p<.001)$, and moderate with CDI $(r=.324, p<.001)$.

\section{Discussion and conclusions}

In this research psychometric properties of the Short LOI-CV were examined in a Spanish community sample of children and adolescents. The EFA yielded a three-factor solution (Obsessions/Incompleteness, Compulsions, and Cleanliness) replicating the same internal structure proposed by Bamber et al. (2002) but obtaining in the current study a greater percentage of accounted variance. The internal consistency coefficients for total score and for Obsessions/Incompleteness subscale were lower than the found by Bamber et al. (2002) but not for Compulsions and Cleanliness subscales. Storch et al. (2011) reported poor values for internal consistency in both, total score and subscales in OCD sample. Differences in internal consistency across studies could be due to the administration of the scale in different populations (clinic vs. community), cultural differences (American, British, and Spanish populations in each one) or as a result of the age range, since the participants in the current study were from 8 to 18 years, whereas participants in Bamber at al. (2002) were only adolescents (from 12 to 16 years). Our findings support a three-factor structure and suggest that the Short LOI-CV can be useful to explore OCD phenomenology in both, epidemiological and clinical studies in community populations of children and adolescents in Spain.

Test-retest reliability was good in this Spanish community sample. The current study is the first to address reliability in the Short LOI-CV, being results similar to those obtained with the long version (King et al., 1995).

In contrast to the results reported by Storch et al. (2011), in the current study, the Short LOI-CV showed a moderate convergent validity with other OCD self-report measures (the OCI-CV and the MOCI). Discriminant validity analysis with a depression measure (CDI) showed a moderate significant correlation.

Finally, weak but significant associations were found between the participants' age, total score, Obsessions/Incompleteness and Compulsions subscales. Overall younger participants (from 8 to 10 years) obtained higher means than older (11-13 and 14-18 years). We also observed significant differences related to the gender. Males showed a significantly higher average score than females in the Compulsions subscale. Similar results have been found in other studies, where the gender was a moderator variable of OCD presentation (De Mathis et al., 2011).

The results in this study suggest that the Short LOI-CV could have an acceptable psychometric performance to screen for obsessive-compulsive symptoms in non-clinical Spanish samples. Clinical diagnosis of OCD is often missed by pediatricians and family doctors, and mental health specialists are sometimes unaware of the misleading symptoms of this disorder. In relation to clinical practice it should be noted that the Short LOI-CV is a brief tool, which allows an easy screening and detection of obsessive-compulsive symptoms. Thus, the short LOI-CV would be useful to acomplish the first recommendation for practice noted in the AACAP (2012) guidelines: the assessment of children and adolescents should include a routinely screening for obsessions and compulsions.

However, these data should be interpreted considering limitations in this study. First, psychometric properties of this measure must be studied in clinical samples of children and adolescents with OCD. Second, the capability of the Short LOI-CV to detect OCD cases and to discriminate OCD from other anxiety and mood disorders should be empirically tested. Third, it would be necessary to examine correlations with measures of global functioning, and to analyze the convergent validity of the Short LOI-CV Spanish version with the CY-BOCS, since it is the gold-standard of assessment in this field. Lastly, the sensitivity and specificity of this measure should be studied more thoroughly. However, despite these limitations and the need for future studies, the Short LOI-CV could be a useful screening tool to detect obsessive-compulsive symptoms in paediatric community population. 


\section{References}

Achenbach, T.M., 1991. Manual for the Child Behavior Checklist/4e18 and 1991 Profile. University of Vermont Department of Psychiatry, Burlington, VT.

American Academy of Child and Adolescent Psychiatry Committee on Quality Issues (2012). Practice parameter for the assessment and treatment of children and adolescents with obsessive-compulsive disorder. Journal of the American Academy of Child and Adolescent Psychiatry, 51, 98-113. doi: 10.1016/j.jaac.2011.09.019

American Psychiatric Association (2013) Diagnostic and statistical manual of mental disorders (text revision). 5th edn, Author, Washington, DC

Bamber, D., Tamplin, A., Park, R. J., Kyte, Z. A., \& Goodyer, I.M. (2002). Development of a short leyton obsessional inventory for children and adolescents. Journal of American Academy of Child and Adolescent Psychiatry, 41, 1246- 1252. doi: 10.1097/00004583-20021000000015

Berg, C. Z., Whitaker, A., Davies, M., Flament, M. F., \& Rapoport, J. L. (1988). The survey form of the Leyton obsessional inventory-child version: Norms from an epidemiological study. Journal of American Academy of Child and Adolescent Psychiatry, 27, 759-763. doi: 10.1097/00004583-198811000-00017

Bloch, M. H., Craiglow, B. G., Landeros-Weisenberger, A., Dombrowski, P. A., Panza, K. E., Peterson, B. S., \& Leckman, J. F. (2009). Predictors of early adult outcomes in pediatric-onset obsessive-compulsive disorder. Pediatrics, 124, 1085- 1093. doi: 10.1542/peds.2009-0015

Canals, J., Hernández-Martínez, C., Cosi, S., Lázaro, L., \& Toro, J. (2011). The Leyton Obsessional Inventory-Child Versión: Validity and reliability in Spanish non- clinical population. International Journal of Clinical and Health Psychology, 12, 81-96.

Cohen, J. (1988). Statistical power analysis for the behavioural sciences (2nd ed.). New York: Academic Press.

De Mathis, M.A., Alvarenga, P.D., Funaro, G., Torresan, R.C., Moraes, I., Torres, A. R., ... \& Hounie, A.G. (2011). Gender differences in obsessive-compulsive disorder: a literature review. Revista Brasileira de Psiquiatria, 33, 390-399.

Flament, M.F., Rapoport, J. L., Whitaker, A., Davies, M., Kalikow, K., \& Shaffer, D. (1988). Obsessive-compulsive disorder in adolescence: An epidemiological study. Journal American Academy of Child \& Adolescent Psychiatry, 27, 764-771. doi: 10.1097/00004583-198811000-00018

Foa, E. B., Coles, M. E., Huppert, J. D., Pasupuleti, R., Franklin, M. E., \& March, J. S. (2010). Development and validation of a child version of the Obsessive Compulsive Inventory. Behavior Therapy, 41, 121132. doi: 10.1016/j.beth.2009.02.001

Fonseca-Pedrero, E., Paino, M., \& Lemos-Giráldez, S. (2007). Psychopedagogica diversity at school: assessment of emotional and behavioural problems. Aula Abierta, 36, 39-48.

Frías, D., Del Barrio, V., \& Mestre, V. (1991). The Children's Depression Inventory (CDI): Its psychometric properties in foreign and Spanish populations. Psychological Assessment, 7, 377-391.

Geller, D. (2006). Obsessive-compulsive and spectrum disorders in children and adolescents. The Psychiatric Clinics of North America, 29, 353-370. doi: 10.1016C/j.psc.2006.02.012

Heyman, I., Fombonne, E., Simmons, H., Ford, T., Meltzer, H., \& Goodman, R. (2001). Prevalence of obsessive-compulsive disorder in the British nationwide survey of child mental health. British Journal of Psychiatry, 179, 324-329. doi: 10.1192/bjp.179.4.324

Hodgson, R.J., \& Rachman, S. (1977). Obsessional-compulsive complaints. Behaviour Research and Therapy, 15, 389-395. doi: 10.1016/00057967(77)90042-0

Huey, S. J., \& Polo, A. J. (2008). Evidence-Based Psychosocial Treatments for Ethnic Minority Youth. Journal of Clinical Child \& Adolescent Psychology, 37, 262-301. doi: 10.1080/15374410701820174

Iniesta-Sepúlveda, M., Rosa-Alcázar, A. I., Rosa-Alcázar, Á., \& Storch, E. A. (2014). Evidence-Based Assessment in Children and Adolescents with Obsessive- Compulsive Disorder. Journal of Child and Family Studies, 23, 1455-1470.

King, N. J., Inglis, S., Jenkins, M., Myerson, N., \& Ollendick, T. H. (1995). Test-retest reliability of the survey form of the Leyton Obsessional
Inventory-Child Version. Perceptual and Motor Skills, 80, 1200-1202. doi: 10.2466/pms.1995.80.3c.1200

Kovacs, M.K. (1992). Child Depression Inventory. New York: Multi-Health Systems. Leonard, H. L., Swedo, S. E., Lenane, M. C., Rettew, D. C., Hamburger, S. D., Bartko, J. J., \& Rapoport, J. L. (1993). A 2-to-7year follow-up study of 54 obsessive- compulsive children and adolescents. Archives of General Psychiatry, 50, 429- 439. doi: 10.1001/archpsyc.1993.01820180023003

Lorenzo-Seva, U., \& Ferrando, P. J. (2006). FACTOR: A computer program to fit the exploratory factor analysis model. Behavioral Research Methods, Instruments and Computers, 38, 88-91. doi:10.3758/BF03192753

Muñiz, J., Elosua, P., \& Hambleton, R. K. (2013). International Test Commission. Guidelies for test translation and adaptation. $2^{\text {nd }} \mathrm{Ed}$. doi: 10.7334/psicothema/2013.24

Rosa-Alcázar, A. I., Iniesta-Sepúlveda, M., \& Rosa-Alcázar, Á. (2012). Effectiveness of cognitive-behavioral therapy for obsessive-compulsive disorder in children and adolescents: a qualitative review. Anales de Psicología, 28, 313-326. doi: 10.6018/analesps.28.2.121461

Rosa-Alcázar, A. I., Ruiz-García, B., Iniesta-Sepúlveda, M., López-Pina, J. A., Rosa- Alcázar, Á. \& Parada-Navas, J. L. (2014). Obsessive Compulsive Inventory-Child Version (OCI-CV) in a Spanish community sample of children and adolescents. Psicothema, 26, 174-179.

Rosa-Alcázar, A. I., Sánchez-Meca, J., Rosa-Alcázar, Á., Iniesta-Sepúlveda, M., Olivares-Rodríguez, J., \& Parada-Navas, J. L. (2015). Psychological Treatment of Obsessive-Compulsive Disorder in Children and Adolescents: a Meta-Analysis. Spanish Journal of Psychology, 18, E20. doi:10.1017/sjp. 2015.22

Roussos, A., Francis, K., Koumoula, A., Richardson, C., Kabakos, C., Kiriakidoy, T.,... \& Karamolegou, K. (2003). The Leyton Obsessional Inventory- Child Version in Greek Adolescents. European Child \& Adolescent Psychiatry 12, 58-66. doi: 10.1007/s00787-003-0308-4

Sánchez-Meca, J., Rosa-Alcázar, A. I., Iniesta-Sepúlveda, M., \& Rosa-Alcázar, A. (2014). Differential Efficacy of Cognitive-Behavioral Therapy and Pharmacological Treatments for Pediatric Obsessive-Compulsive Disorder: A Meta-analysis. Journal of Anxiety Disorders, 26, 31-44. doi: 10.1016/j.janxdis.2013.10.007

Scahill, L., Riddle, M. A., McSwiggin-Hardin, M., Ort, S. I., King, R. A., Goodman, W. K., ... \& Leckman, J. F. (1997). Children's YaleBrown Obsessive Compulsive Scale: Reliability and validity. Journal of the American Academy of Child and Adolescent Psychiatry, 36, 844-852. doi:10.1097/00004583-199706000-00023

Shafran, R., Frampton, I., Heyman, I., Reynolds, M., Teachman, B., \& Rachman, S. (2003). The preliminary development of a new selfreport measure for OCD in young people. Journal of Adolescence, 26, 137-142. doi:10.1016/S0140- 1971(02)00083-0

Stewart, S. E., Ceranoglu, T. A., O’Hanley, T., \& Geller, D. A. (2005). Performance of clinician versus self-report measures to identify obsessive-compulsive disorder in children and adolescents. Journal of Child and Adolescent Psychopharmacology, 15, 956-963. doi:10.1089/cap.2005.15.956

Storch, E. A., Khanna, M., Merlo, L. J., Loew, B. A., Franklin, M., Reid, J. M., ... \& Murphy, T. K. (2009). Children's Florida Obsessive Compulsive Inventory: Psychometric properties and feasibility of a self-report measure of obsessive- compulsive symptoms in youth. Child Psychiatry \& Human Development, 40, 467-483. doi: 10.1007/s10578-009-0138-9

Storch, E. A., Park, J. M., Lewin, A. B., Morgan, J. R., Jones, A. M., \& Murphy, T. K. (2011). The Leyton Obsessional Inventory-Child Version Survey Form does not demonstrate adequate psychometric properties in American youth with pediatric obsessive-compulsive disorder. Journal of Anxiety Disorders, 25, 574-578. doi: 1016/j.janxdis.2011.01.005

Timmerman, M.E., \& Lorenzo-Seva, U. (2011). Dimensionality assessment of ordered polytomous items with Parallel Analysis. Psychological Methods, 16, 209-220. doi: 10.1037/a0023353

(Article received: 13-07-2015; revised: 22-07-2015; accepted: 23-07-2015) 